\title{
К МОДЕЛИ РАЗВИТИЯ ДАЛЬНЕВОСТОЧНЫХ ТЕРРИТОРИЙ: РЕАЛЬНОСТЬ И ПЕРСПЕКТИВЫ
}

\author{
(c) 2018 Зельднер Алексей Григорьевич \\ доктор экономических наук, профессор, главный научный сотрудник \\ Институт экономики РАН \\ E-mail: tzeldner@gmail.com
}

Приоритетное развитие Дальневосточного федерального округа связано не только с природным потенциалом этого региона, но и с соседством со странами Азиатско-Тихоокеанского региона, обладающими инвестиционным и технологическо-инновационным потенциалом. Одобренная Правительством модель развития Дальнего Востока предполагает привлечение прямых инвестиций, в том числе иностранных. Вариант решения этой задачи в статье предлагается за счет привлечения высокотехнологичных зарубежных технологий на концессионной основе и методов страхования рисков концессионеров. Статья написана при поддержке РФФИ (РГНФ), грант 16-02-00-141.

Ключевые слова: территории опережающего развития, модель развития, технологии, инновации, экономические рычаги, концессии.

Введение: институциональные основы модели развития Дальневосточного федерального округа (ДФО)

Складывающаяся социально-экономическая и политическая обстановка в России вынуждает искать варианты для приоритетного развития регионов, граничащих с высокоразвитыми странами и относительно спокойно воспринимающими низкие темпы экономического роста и введенные против России санкции. Таким регионом на данном этапе развития становится Дальний Восток, ориентированный на страны ATP (Китай, Япония, Южная Корея и другие), которые заинтересованы в потенциальных возможностях ДФО и, как показал начальный период формирования территорий опережающего социально-экономического развития (ТОСЭР), участвующие в качестве инвесторов и резидентов.

Учитывая геополитическое положение ДФО и его потенциальные возможности привлечения зарубежных инвестиций, Дальневосточный регион априори становится зоной приоритетного развития, широко используя новые локализованные формы пространственного развития, такие как ТОСэР, особые экономические зоны, индустриальные парки, что позволит России, при прочих равных условиях, обеспечить технологическое развитие региона.

В октябре 2013 г. Правительство РФ одобрило предложенную Минвостокразвития модель развития Дальнего Востока, основанную на «экспорте в страны Азиатско-Тихоокеанского региона готовых товаров (работ, услуг), создании конкурентоспособного инвестиционного климата, привлечении прямых инвестиций, в том числе иностранных, на росте деловой активности, развитии малого и среднего предпринимательства, создании конкурентоспособных территорий опережающего социально-экономического развития, комплексном развитии Дальнего Востока» [1].

Следует особо отметить, что модель не замыкается только на Дальневосточном федеральном округе. Одним из существенных моментов одобренной правительственной комиссией модели развития Дальнего Востока становится обеспечение международной конкурентоспособности создаваемых форм развития в ДФО в привлечении прямых зарубежных инвестиций.

Для реализации поставленной в модели развития Дальнего Востока цели создана основа институциональной базы, включающая систему законов и нормативных актов Правительства России. Среди них Федеральный закон «О территориях опережающего социально-экономического развития в Российской Федерации» от 29.12.2014 г. № 473-ФЗ. Федеральный закон от 1.05 .2016 г. № 119-Ф3 «Об особенностях предоставления гражданам земельных участков... на территории ДФО...», Закон о свободном порте Владивосток и др. Были сформированы ин- 
ституты развития: Министерство Российской Федерации по развитию Дальнего Востока“; Корпорация развития Дальнего Востока, обеспечивающая строительство инфраструктуры; Агентство развития человеческого капитала и Агентство Дальнего Востока по привлечению инвестиций и поддержке экспорта.

Принятию модели способствовал выход ряда базовых правительственных постановлений и Указов Президента, направленных на отработку отдельных направлений модели пространственного развития Российской Федерации, касающейся и ДФО. Так, в августе 2015 г. выходит постановление Правительства РФ «О содержании, составе, порядке разработки и утверждения стратегии пространственного развития РФ...», в котором рассматриваются приоритетные направления размещения производительных сил на территории РФ. В 2016 г. Минэкономразвития РФ подготовило проект Концепции «Стратегия пространственного развития РФ на период до 2030 г.». В 2017 г. публикуется Указ Президента РФ от 16.01.2017 г. № 13 «Об утверждении основ государственной политики регионального развития РФ на период до 2025 г.» [2], в котором ставятся «приоритетные задачи и механизмы реализации госполитики регионального развития с учетом стратегических национальных интересов». В Указе зафиксирован «дифференцированный подход к реализации мер господдержки регионов и муниципальных образований в зависимости от их социально-экономических и географических особенностей». Одновременно четко обозначена необходимость «снятия инфраструктурных ограничений для опережающего развития территорий с низким уровнем социально-экономического развития... низкой плотностью населения и прогнозируемым наращиванием экономического потенциала» [2]. В общем, эта позиция определяет и отношение к формированию территорий опережающего развития, ДФО как приоритетную пилотную для страны модель с учетом встраивания в международную интеграцию, в первую очередь, со странами АТР, (как звена, способного потянуть за собой технологическое и инновационное развитие страны) в условиях реально происходящей трансформации мировой экономики в соответствии с четвертой промышленной революцией, обеспечивающей развитие всех новейших технологий, меняющих производственные процессы и повышающих конечные результаты.

\section{Инвестиционное обеспечение модели развития ДФО.}

Реализация модели приоритетного развития ДФО предполагает бюджетное обеспечение формирования инфраструктуры, имеется ввиду бюджеты всех уровней и возможности использования современных научных достижений, как отечественных, так и зарубежных. Рассмотрим подробнее состояние этих двух составляющих, обеспечивающих прогрессивное развитие экономики.

О состоянии бюджетного финансирования. В принятом правительством федеральном законе «О территориях опережающего развития в Российской Федерации» № 473-ФЗ от 29.12.2014 г. определено финансирование инфраструктуры за счет бюджетов всех уровней и внебюджетных источников. Еще один источник финансирования - наличие во всех ключевых госпрограммах страны спецразделов по ДФО. Следует отметить, что в условиях усложнения политической и экономической обстановки наблюдается существенная корректировка инвестиционных планов. Так, в соответствии с трехлетним бюджетом на 2018 г. и на плановый период до 2019 г. и 2020 гг. по целевой госпрограмме «Социально-экономическое развитие Дальнего Востока и Байкальского региона» финансирование устойчиво снижается с 33,7 млрд. руб. в 2018 г. до 17,7 млрд. руб. в 2019 г. и 16,9 млрд. руб. в 2020 г. Сложное положение и по другим источникам финансирования ДФО. В утвержденных правительством перечне программ, в которых обязан быть дальневосточный раздел, «предусмотрено только $3,3 \%$ от общего объема финансирования». При этом следует учесть, что это только планы.

К этому следует добавить, что хотя инвестиции в России в текущих ценах в основной капитал в стране растут (с 2013 г. по 2016 г. (включительно) они выросли на 8,8\%), в сопоставимых, начиная с 2013 г. наблюдается снижение в процентах к 1990 г. с 76,2\% в 2013 г. до 66,9\% в 2016 г. [3, c.38]. Снижение объема инвестиций в сопоставимых ценах отразилось и на выполнении феде-

\footnotetext{
" Функции Министерства включают: координацию и реализацию приоритетных проектов; распорядителя бюджетных средств в отношении субсидий на развитие социальной и инженерной инфраструктуры; участие в зонах территориального развития; привлечение инвестиций; управление человеческим капиталом и другие.
} 
ральной адресной инвестиционной программы на 2016 г. Из плановых инвестиционных объектов на 2016 г. в количестве 443 единиц фактически введено на полную мощность 165 объектов [3, с.177], это 37,2\% плана.

В России принята программа «дереструктуризации региональных бюджетных кредитов, общая сумма которых около 0,7 трлн. руб.,, которые должны быть погашены разными долями до 2024 г.» [4]. Рост задолженности регионов системная проблема. Это влияние, как внешних факторов, так и внутренних, обусловленных необходимостью выполнения майских указов президента и медленным ростом доходов большинства регионов. Отсюда необходимость бюджетных и рыночных кредитов и рост задолженности. В то же время с 2015 г. вводятся ограничения на бюджетные кредиты по критерию платежеспособности региона.

Одновременно принимаются меры (Минфином) по сжатию расходной части региональных бюджетов. Ужесточение Минфина по сокращению расходов регионов, включая выдачу бюджетных кредитов, вынуждает регионы активизироваться на коммерческом рынке. Но если бюджетные кредиты и казначейские займы (под 0,1\% на 50 дней) выдавались на льготных условиях, то процентные ставки в коммерческих банках были существенно выше.

С позиции Минфина понятно желание сократить расходы региональных бюджетов, но необходимо помнить о наличии обязательств многих регионов, подтвержденных законодательно, о стимулировании привлечения инвестиций в территории опережающего социально-экономического развития и др., которые предусматривают налоговые льготы для привлечения резидентов.

Сжатие бюджетных расходов регионов, инициированное Минфином, осуществляется параллельно с оптимизацией налоговых распределений «Центр-регионы». Так, «налог на пользователей автомобильных дорог, централизация водного налога, доходов от уплаты акцизов на алкогольную продукцию, уменьшение нормативов по отчислениям в бюджеты регионов по налогу на прибыль организаций, обнуление налога на прибыль организаций и налога на добычу полезных ископаемых для предприятий осуществляющих инвестиционные проекты. Все это приведет к совокупным потерям доходов региональных бюджетов» [5]

В конце 2014 г. принимается ФЗ от 31.12.2014 № 488-Ф3 «О промышленной политике в РФ», в котором целями промышленной политики обозначается «формирование высокотехнологичной конкурентоспособной промышленности, обеспечивающей переход экономики государства от экспортно-сырьевого типа развития к инновационному типу развития». Обоснованное и современное направление развития экономики. Но при этом напряжение с инвестициями из-за низких темпов развития в стране возрастает. И при этом предпринимается попытка переложить часть федеральных финансовых обязательств на региональные и муниципальные бюджеты. Так, в соответствии с ФЗ № 488-Ф3 (ст. 7, п. 1), государственные власти субъектов устанавливают «меры стимулирования деятельности в сфере промышленности за счет средств бюджетов субъекта РФ», а органы местного самоуправления (ст. 8) вправе осуществить меры стимулирования в сфере промышленности на своей территории ... «за счет доходов местных бюджетов ... и поступлений налоговых доходов по дополнительным нормативам отчислений». Эти «меры стимулирования» коснулись, в первую очередь, всех новых форм пространственного развития. Все это происходит на фоне роста совокупного госдолга регионов, которые с 2006 г. вырос до 2,3 трлн. руб. в основном за счет бюджетных и банковских кредитов (Эксперт № 4, 2017 г.).

Как показывает отечественный опыт финансирования инфраструктуры ОЭЗ" и ТОСЭР, федеральный бюджет недовыполняет свои обязательства. В этих условиях возрастает нагрузка на регионы, а в регионах, как мы отметили выше, существенна бюджетная задолженность. Отсюда необходимость бюджетных и рыночных кредитов и рост задолженности. В то же время с 2015 г. вводятся ограничения на бюджетные кредиты по критерию платежеспособности региона.

Как следствие, недофинансирование социальной сферы. Так, по разделу «Здравоохранение» расходы консолидированного бюдже-

\footnotetext{
* Финансирование инфраструктуры ОЭЗ за счет федерального бюджета на 2011-2013 гг. было заложено со снижением объема инвестиций. Так на 2011 г. Управляющей компании ОАО «Особые экономические зоны» выделялось 15,67 млрд. руб., на 2012 г.- 6,03 млрд., и эта же сумма выделялась на 2013 г. (Российская газета. 2010.17.12)
} 
та регионов Дальнего Востока лишь немного превысили половину расходов предыдущего 2016 г. - 57\%. В сумме - это 50 млрд. рублей [6]. При таком подходе к социальной сфере миграция населения ДФО будет продолжаться. В 2017 г. регион покинуло 17 тысяч человек.

Что касается проблемы финансирования территорий опережающего социально-экономического развития (ТОСЭР), то следует отметить, что эффект начальной стадии себя оправдал. Так, в 2017 г. в целом по Дальневосточному федеральному округу прирост инвестиций был в 2,5 раза выше, чем в среднем по России. Но этот прирост в определенной степени был обеспечен строящимися в Амурской области в ТОСЭР «Свободный» газоперерабатывающего завода, инвестиции первого этапа около 1 трлн. рублей. Следует отметить, что в целом по Амурской области объем инвестиций в три ТОСЭР - 1,1 трлн. руб., это 50\% всего объема инвестиций в дальневосточные территории опережающего развития.

Учитывая слабую инфраструктурную обеспеченность ДФО, сложные климатические условия, продолжающийся отток населения, возникают сложности с привлечением частных инвестиций и инвесторов. За последние 4 года реальный удельный вес частных инвестиций составил 3,3\% от общего количества заявленных [6]. Это свидетельствует о том, что без существенного увеличения бюджетных вложений, активного участия крупных холдингов и корпораций, создания условий для использования механизмов ГЧП и, в частности, такой апробированной формы как концессии, развитие ДФО на базе новейших технологий может существенно затянуться.

Эффективное функционирование территорий опережающего развития в условиях ограничения федеральных и региональных инвестиций возможно за счет расширения использования механизмов ГЧП и передачи регионам дополнительных полномочий из тех, которые находятся в совместном ведении с Российской Федерацией. Учитывая достаточно глубокую дифференциацию регионов по их финансовым возможностям, необходимо наделить их дополнительными полномочиями, направленными на пополнение инвестиционных источников. Исходя из главы 3 «Федеративное устройство» Конституции РФ и опираясь на Закон о территориях опережающего развития, целесообразно наделить регионы большими правами в налогообложении, в использовании государственной собственности, природных ресурсов и других льгот и прав, позволяющих обеспечить условия для привлечения как отечественных, так и иностранных инвесторов с целью быстрейшей реализации программы по освоению территорий опережающего развития. С передачей регионам дополнительно части функций, находящихся в совместном ведении, появляется, при прочих равных условиях, возможность налаживания реального воспроизводственного процесса в регионе и улучшение качества управления регионом.

\section{Инновационная составляющая развития} прогрессивных технологий в ТОСЭР

Идущая трансформация мировой экономики в соответствии с четвертой промышленной революцией кардинально меняет все производственные и управленческие процессы, и намечающееся отставание в этой сфере чревато потерями конкурентоспособности российской несырьевой (гражданской) экономики. Это приведет к тому, что Россия прочно утвердится в числе догоняющих стран мира с развитой сырьевой экономикой, тесно зависимой от конъюнктуры мировых цен на сырье и темпов развития альтернативных энергетических источников.

Следует отметить, что складывающаяся ситуация понимается, и формально проводятся определенные действия. Так, в 2017 г. утверждена «дорожная карта» по развитию национальной технологической инициативы «Передовые производственные технологии». Но, как отмечает директор Международного центра программ и проектов в бизнес-образовании РАНХиГС А. Пивоваров, «на практике реальных результатов пока не видно» [7].

Проблема встраивания России в происходящую трансформацию мировой экономики на современном этапе достаточно многоаспектна. Частично она определяется сырьевым лобби, получающим устойчиво сырьевую ренту и очень слабо участвующим в инновационных разработках*. Существенную роль играет и состояние бюджета в условиях политической не-

\footnotetext{
* Удельный вес инновационной активности организаций в сфере добычи топливно-энергетических полезных ископаемых в общем числе обследованных снижается: в 2003 г. он составлял 7,2\%, в 2014 г. - 7,4\%, в 2015 г.6,3\%, в 2016 г. - 5,6\%. (Наука, технологии и инновации в России 2017. М. ИПРАН РАН. 2017. С. 76).
} 
стабильности, учитывающего приоритет национальной безопасности". Немаловажное влияние оказывают и введенные против России санкции, приведшие к разрыву интеграционных связей и необходимости финансировать процесс импортозамещения. Но, при всех прочих условиях, страна должна приоритетно активизировать свою деятельность в направлении ускорения трансформации экономики на новейшей технологической и инновационной основе.
В этом плане необходимо решение первоочередной задачи по обеспечению приоритетного развития гражданской науки в стране, как основы технологического прогресса гражданской экономики и экономической безопасности страны. Для финансирования развития науки, помимо традиционных источников, следует ввести целевой рентный налог на все сырьевые производства, как частные, так и государственные.

\section{Библиографический список}

1. https://minvr.ru/press-center/news/895/

2. http://kremlin.ru/acts/bank/41641

3. Инвестиции в России 2017. Москва. Россстат. 2017.

4. Маврина Л. Оттолкнулись от дна и всплывают // Эксперт № 4. 2017. С. 97

5. Эксперт № 45. 2017. С. 39.

6. https://minvr.ru/press-center/news/13581/

7. Российская газета. Экономика. 24.05.2018. С. 16.

\footnotetext{
" Государственная политика регионального развития реализуется «с учетом стратегических национальных приоритетов РФ...» (Указ Президента РФ «Об утверждении основ государственной политики регионального развития РФ на период до 2025 .» от 16.01.2017 г. № 13, пункт 4), а также факторов и условий неравномерного размещения производительных сил и расселения населения на территории страны и различий в уровне социально-экономического развития регионов.
} 